\title{
The Effects of Boswellia serrata Gum Resin on the Blood Glucose and Lipid Profile of Diabetic Patients: A Double-Blind Randomized Placebo-Controlled Clinical Trial
}

Journal of Evidence-Based Integrative Medicine Volume 23: $1-7$ (C) The Author(s) 2018 Reprints and permission: sagepub.com/journalsPermissions.nav DOI: 10.1 I77/25। $5690 \times 18772728$ journals.sagepub.com/home/cam @SAGE

\author{
Saeed Mehrzadi, PhD', Bahreh Tavakolifar, PhD², Hasan Fallah Huseini, PhD ${ }^{3}$, \\ Seyed Hamdollah Mosavat, PhD $^{4}$, and Mojtaba Heydari, PhD $^{4}$
}

\begin{abstract}
Regarding preclinical evidence for antidiabetic effects of Boswellia serrata, we evaluated antihyperglycemic and lipid-lowering effects of Boswellia serrata gum resin in type 2 diabetic patients. Fifty-six diabetic patients were randomly allocated to 2 groups to receive $250 \mathrm{mg}$ of the Boswellia serrata gum resin or placebo twice daily for 8 weeks in addition to their routine antidiabetic treatments. Although there was a considerable reduction after the intervention in the field of fasting blood sugar, glycosylated hemoglobin, and triglyceride in the Boswellia serrata gum resin group, no significant difference was observed in all outcome measures between the 2 groups at the end of the study. The current study showed that 8 weeks of complementary use of Boswellia serrata gum resin with a daily dose of $500 \mathrm{mg}$ had no better glucose and lipid-lowering effect than placebo in diabetic patients.
\end{abstract}

\section{Keywords}

Boswellia serrata, diabetes mellitus, complementary and alternative medicine, herbal medicine

Received August 5, 2017. Accepted for publication December 24, 2017.

Diabetes mellitus, as one of the most common noncommunicable and chronic diseases in the world, especially in low/middleincome countries, has a growing prevalence. ${ }^{1}$ In 2014, about 387 million people worldwide were afflicted with diabetes, with many cases undiagnosed. ${ }^{2}$ The diabetes prevalence in Iran is estimated to be $7.7 \%$ in adults. ${ }^{3}$ Diabetic patients suffer from a variety of related diseases such as dyslipidemia, which increases their cardiovascular risk. Since diabetic patients with dyslipidemia have a higher mortality rate compared with diabetes mellitus individuals with no dyslipidemia, prevention and management of dyslipidemia in these patients seems be essential. ${ }^{4,5}$

Nowadays, there is an increasing interest toward complementary and alternative medicine. ${ }^{6,7}$ Also, because of insufficient efficacy and prominent adverse effects of the current therapies for hyperlipidemia, diabetes and its complications, there is an increasing interest in complementary and alternative therapies especially the use of medicinal plants in treatment of this disease. ${ }^{8-12}$ Because of the mentioned comorbidity of diabetes and hyperlipidemia, medicinal plants with concurrent glucose and lipid-lowering effects are an area of research interest. ${ }^{13-15}$
Boswellia serrata (commonly known as Salai in India and Kondor in Arabic) is one of the medicinal plants that is traditionally used to treat various diseases, including diabetes. ${ }^{16-19}$ Previous studies showed anti-inflammatory, antiulcerous activities, and anti-cancerous effects of this plant. ${ }^{20}$ Antihyperglycemic and antihyperlipidemic effects of Boswellia serrata in streptozotocin-induced diabetic rats have been shown in other

\footnotetext{
I Razi Drug Research Center, Iran University of Medical Sciences, Tehran, Iran

2 Alborz University of Medical Sciences, Karaj, Alborz, Iran

${ }^{3}$ Medicinal Plants Research Center, Institute of Medicinal Plants, ACECR, Karaj, Iran

${ }^{4}$ Research Center for Traditional Medicine and History of Medicine, Shiraz University of Medical Sciences, Shiraz, Iran
}

\section{Corresponding Author:}

Hasan Fallah Huseini, PhD, Medicinal Plants Research Center, Institute of Medicinal Plants, Academic Center for Education, Culture and Research (ACECR), Karaj, Iran.

Email: huseini_fallah@yahoo.com 
studies as well. ${ }^{20,21}$ Moreover, a study showed that Boswellia serrata has protective effects on diabetic complications in animal model. ${ }^{22}$ It also has showed beneficial effects on blood glucose, low-density lipoprotein (LDL), and high-density lipoprotein (HDL) of diabetic patients with the daily dose of 900 $\mathrm{mg}$ without any important side effect. ${ }^{23,24}$ According to increase in serum insulin of patients who received Boswellia serrata, it is supposed that its antihyperglycemic effect is through increase in insulin secretion. ${ }^{23,24}$

Regarding previously determined antihyperglycemic effect of Boswellia serrata in animal models and also in one dose in human, this study aimed to reevaluate antihyperglycemic and lipid-lowering effects of Boswellia serrata gum resin in type 2 diabetic patients in lower dose $(500 \mathrm{mg} / \mathrm{d})$ in a double-blind randomized placebo-controlled trial.

\section{Materials and Methods}

\section{Preparation of Drugs}

The Boswellia serrata with certified botanical origin India (standardized for $60 \%$ Boswellic acids by Himalayan Herbaria Inc, India), was purchased from herbal market, Karaj, Iran. It was ground into powder. The gum powder as an intervention drug and toast powder due to relative similarity to the gum powder, as a placebo, were separately filled into oral gelatin capsules $(250 \mathrm{mg}$ ) with identical appearance by using a hand-operated capsule-filling machine (Scientific Instruments and Technology Corporation).

\section{Phytochemical Assay}

Thin layer chromatography was used for recognizing chemical components of resin. A variety of indicators, including vanillin sulfuric acid, ferric chloride, and natural product polyethylene glycol were used in this assay. The indicators were sprayed on the prepared thin layers of fractions and observed at 260 and $280 \mathrm{~nm}$ wavelengths under ultraviolet light.

\section{Identification of the Volatile Oil Constituents}

The volatile essential oils obtained by hydrodistillation of Boswellia serrata (volatile oil 10\%) were analyzed using an Agilent $6890 \mathrm{GC}$ equipped with BPX5 capillary columns $(30 \mathrm{~m} \times 0.25 \mathrm{~mm}$, inner diameter $0.25 \mu \mathrm{m}$ film thicknesses) and a mass spectrometer column temperature was gradually increased from $50^{\circ} \mathrm{C}$ to $240^{\circ} \mathrm{C}$ with a rate of $3^{\circ}$ $\mathrm{C} / \mathrm{min}$. For gas chromatography/mass spectrometry detection, electron ionization system was used with ionization energy of $70 \mathrm{eV}$. The injector and ion source temperatures were set at $290^{\circ} \mathrm{C}$ and $220^{\circ} \mathrm{C}$, respectively. One microliter of the sample was injected manually in splitless mode. C9-C20 $n$-alkanes were used as reference points in calculation of the Kovats indices (KI). Tentative identification of the compounds was done based on the comparison of their relative retention time and mass spectra with those of the NIST and Wiley library data of the gas chromatography/mass spectrometry system and literature data. ${ }^{25}$

\section{Trial Design}

The trial is a 2-arm, double-blind randomized placebo-controlled clinical trial using a parallel design with a 1:1 allocation ratio. There was no change in methods after trial commencement.

\section{Participants and Intervention}

A total of 384 patients who referred to a private diabetic health care center in Karaj, Iran, during March 2014 and October 2014 were evaluated for inclusion in the study. All the patients were visited by the investigator; if they met the inclusion criteria, they were enrolled in the study. Inclusion criteria for the participants were 18- to 65-yearold patients with type 2 diabetes according to the American Diabetes Association criteria with fasting blood sugar $(\mathrm{FBS})=140-180 \mathrm{mg} / \mathrm{dL}$, glycosylated hemoglobin (HbA1c) $7 \%$ to $9 \%$. Exclusion criteria were pregnancy; lactation; nursing women; and patients on insulin, oral and topical steroid, and diuretic agents. Also, patients with serious cardiac, renal, hepatic or hematological diseases, hypothyroidism, tachycardia, vertigo, and seizure were excluded. At last, 56 patients were allocated to the intervention and control groups. The enrolled patients were randomly assigned to receive Boswellia serrata gum capsule $(\mathrm{n}=27)$ as the intervention group or placebo $(\mathrm{n}=29)$. Patients received Boswellia serrata gum $250 \mathrm{mg}$ capsules or placebo capsules twice daily after meal for 8 weeks. Consumption of conventional oral hypoglycemic agents was continued in the 2 groups simultaneously. The patients' compliance was checked via asking on the number of missed dose in their visit.

\section{Sample Size}

The sample size was calculated as 25 patients in each group to estimate $20 \mathrm{mg} / \mathrm{dL}$ difference of FBS between the groups, considering type I error $=0.05,80 \%$ power. $^{26}$

\section{Randomization, Blinding, and Allocation Concealment}

Fifty-six eligible patients were randomized after signing the consent form in 2 parallel groups (Boswellia serrata gum capsule as the intervention group and placebo group) by the investigator. The randomized list was generated using Microsoft Excel with a block randomization, with block size of 4 , as previously shown. ${ }^{27}$ The investigator, drug deliverers, and statisticians were blind to the allocation of the patients. Moreover, because of the same shape and size of the intervention and placebo capsules, the patients were blind to the drug allocation.

\section{Ethical Considerations}

This trial is a 2-arm, double-blind randomized placebo-controlled clinical trial that was registered by the American Economic Association's registry for randomized controlled trials with a code: AEARCTR-0000898. The local Medical Ethics Committee of Qazvin University of Medical Sciences approved the trial protocol (reference number: $2741 / 20 / د)$ and written informed consent was obtained from each patient prior to the study. This study compared Boswellia capsule with placebo and both groups received routine hypoglycemic agents to avoid any deprivation from the standard treatment.

\section{Outcomes}

Mean values for the FBS, HbAlc as primary outcome measures and total cholesterol, LDL, HDL, triglyceride, and insulin level as secondary outcome measures were determined at the baseline and 8 weeks after the intervention in both groups. Blood samples were drawn after an overnight (12 hours) fasting and sent to the hospital's central laboratory. All the blood sample parameters were measured by using 
Table I. Phytochemical Results of the Boswellia serrata Gum Resin.

\begin{tabular}{lllc}
\hline Components & Solvent Systems & Reagents & Result \\
\hline $\begin{array}{c}\text { Terpenoids and } \\
\text { phenylpropanoids }\end{array}$ & $\begin{array}{c}\text { n-Hexane:ethyl } \\
\text { acetate (7.2:2.8) }\end{array}$ & $\begin{array}{c}\text { Vanillin sulfuric } \\
\text { acid }\end{array}$ & + \\
$\begin{array}{c}\text { Phenolic } \\
\text { components }\end{array}$ & $\begin{array}{c}\text { Chloroform:ethyl } \\
\text { acetate:formic } \\
\text { acid (5:4:1) }\end{array}$ & Ferric chloride & + \\
Flavonoids & $\begin{array}{c}\text { Ethyl acetate:methanol: } \\
\text { water (100:13.5:10) }\end{array}$ & $\begin{array}{c}\text { Natural product } \\
\text { reagent }\end{array}$ & + \\
& & & \\
\hline
\end{tabular}

Table 2. The Constituents of Essential Oil of Boswellia serrata by Gas Chromatography/Mass Spectrometry.

\begin{tabular}{llr}
\hline & Components & $\%$ \\
\hline 1 & $\alpha$-Thujene & 16.12 \\
2 & $\alpha$-Pinene & 25.31 \\
3 & Myrcene & 13.23 \\
4 & p-Cymene & 10.78 \\
5 & Limonene & 2.02 \\
6 & Methyl chavicol & 5.43 \\
7 & $\beta$-Elemene & 4.01 \\
8 & Sabinene & 2.03 \\
9 & Cadinene & 2.62 \\
10 & Camphene & 3.10 \\
11 & $\beta$-Phellandrene & 4.06 \\
12 & Unknown components & 11.29 \\
\hline
\end{tabular}

DSS Pink-300 test kit (Drew Scientific Limited, UK) kits in the hospital's central laboratory.

\section{Statistical Methods}

The descriptive data were presented as numbers, frequencies, means, and standard deviations. The paired and independent Student $t$ test and chi-square test were used for statistical comparison of primary characteristics and outcomes between the drug and placebo groups. The intention-to-treat analysis protocol was used for analysis of the data of patients who did not fully adhere to the study protocol. A $P$ value less than .05 was considered significant. SPSS software (version 17, IBM Corporation, Armonk, NY) was used for analysis of data.

\section{Results}

\section{Phytochemical Assay}

Phytochemical assay by thin layer chromatography showed the main components, including phenyl propanoids, terpenoids, phenolic compounds, and flavonoids that were present in the resin (Table 1).

\section{Essential Oil Constituents}

The major components of the essential oil of Boswellia serrata by gas chromatography/mass spectrometry were $\alpha$-thujene, $\alpha$-pinene, myrcene, and $p$-cymene (Table 2).

\section{Baseline Characteristics Data}

During the study, a total of 384 patients were assessed for eligibility, and finally 56 of them were included in the trial and randomized to receive the trial or placebo drug. Figure 1 is a flowchart of the group allocation, enrolment, intervention, follow-up, and result analysis. The patients were reassessed 8 weeks after the intervention. No adverse reaction was reported by the patients. Two patients of the placebo group discontinued the study drug, but they were included in the analysis according to intention-to-treat protocol analysis.

The percentage of female study participants in the intervention and placebo groups was $63 \%$ and $45 \%$, respectively. Other baseline characteristics for each group (age and duration of the disease) are shown in Table 3 as the mean \pm standard deviation for continuous variables. There was no significant difference between basic characteristics of the 2 groups $(P>.05)$.

\section{FBS, HbAlc, Total Cholesterol, LDL, HDL, Triglyceride, and Insulin Levels}

There was also no significant difference between the states of outcome measures in the 2 study groups before the intervention (FBS $P=.54$, HbA1c $P=.98$, total cholesterol $P=.08$, LDL $P=.12$, HDL $P=.60$, triglyceride $P=.20$, and insulin $P=.20$ ).

There was a considerable reduction after the intervention in the field of FBS $(P=.04), \mathrm{HbA1c}(P=.02)$, and triglyceride $(P=.01)$ in the Boswellia serrata gum resin group. There was no significant change in outcome measures in the placebo group (Table 4).

No significant difference was observed in all the outcome measures between the 2 groups at the end of the study (FBS $P=.09$, HbAlc $P=.20$, total cholesterol $P=.31$, LDL $P=.49$, HDL $P=.10$, triglyceride $P=.78$, and insulin $P=.86$ ). Table 4 shows the details of the changes of outcome measures.

\section{Adverse Events}

There was no reported adverse event by the patients in the 2 groups of the study.

\section{Discussion}

In the present study, we evaluated antihyperglycemic and lipidlowering effects of Boswellia serrata gum resin in type 2 diabetic patients in a double-blind randomized placebo-controlled clinical trial. Results of this trial showed that although there was a reduction after the intervention in the field of FBS $(P=.04), \mathrm{HbA1c}(P=.02)$, and triglyceride $(P=.01)$ in the Boswellia serrata gum resin group, these changes were not statistically significant compared with the placebo group. Thus, use of Boswellia serrata gum resin in $500 \mathrm{mg}$ daily dose for 8 weeks failed to demonstrate significantly better effect on glycemic control and lipid profile in diabetic patients compared with the placebo group.

Multiple herbal remedies have been assessed previously for their antihyperglycemic and lipid-lowering effects. In Chinese herbal medicine, Xianzhen Pian, Qidan Tongmai, and Liuwei 


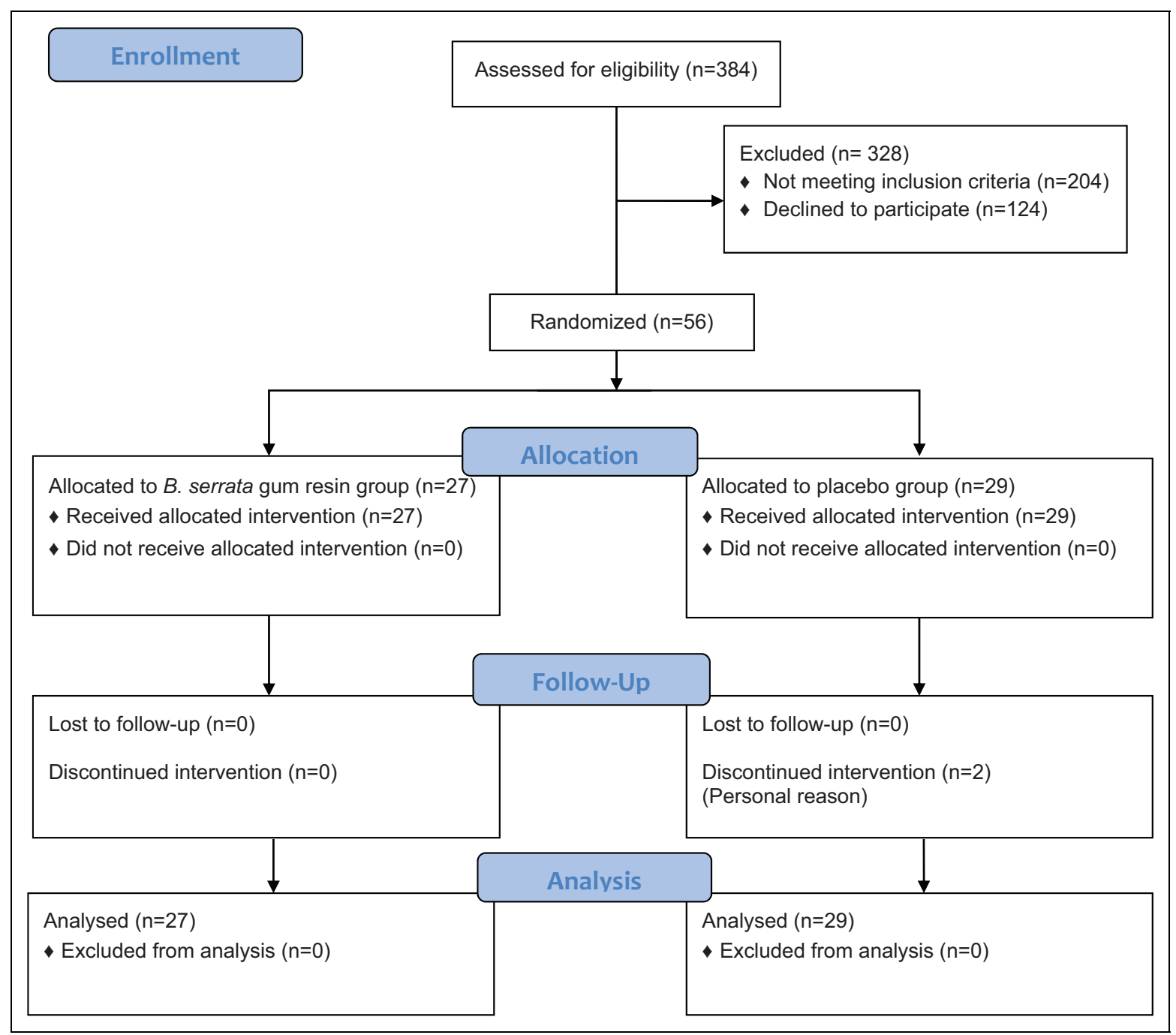

Figure I. Flowchart of study inclusion, allocation, and follow-up.

Table 3. The Baseline Demographic Information of the Patients in Boswellia serrata Gum Resin and Placebo Groups.

\begin{tabular}{lccc}
\hline Basic Characteristics & $\begin{array}{c}\text { Boswellia } \\
\text { Gum Resin }\end{array}$ & Placebo & $P$ \\
\hline $\begin{array}{l}\text { Sex, women, \% } \\
\text { Age, years, mean } \pm \text { SD }\end{array}$ & $57.07 \pm 10.08$ & $52.68 \pm 10.69 .16$ \\
$\begin{array}{c}\text { Duration of diabetes, years, } \\
\text { mean } \pm \text { SD }\end{array}$ & $11.44 \pm 6.80$ & $10.82 \pm 6.00$ & .81 \\
$\begin{array}{c}\text { Mean body mass index, } \mathrm{kg} / \mathrm{m}^{2}, \\
\quad \text { mean } \pm \text { SD }\end{array}$ & $26.01 \pm 2.42$ & $25.06 \pm 2.03$ & .13 \\
\hline
\end{tabular}

Dihuang Tang are common herbs that are traditionally used and have approved antihyperglycemic effect. ${ }^{28}$ Also, in non-Chinese traditional medicine such as traditional Persian medicine, there are several herbs that were significantly effective in reduction of blood glucose such as Citrullus colocynthus L., Silybum marianum, Psyllium, Teucrium polium, and pomegranate. ${ }^{9,29}$ Dill, fenugreek, ginger, ginseng, green tea, and Nigella are also reported to have hypolipidemic effects. ${ }^{30}$
Many herbs have been used to control the blood sugar and approved their effects. However, diabetic patients usually have multiple comorbidities, which lead to polypharmacy and increase the risk of drug interactions, ${ }^{31}$ so the trend of researches in the field of herbal medicine is toward the herbs that affects multiple metabolic targets. For example, researches on Aloe vera L, Brassica napus, Trigonella foenum-graecum, Juglans regia $\mathrm{L}$, and Hibiscus sabdariffa have shown positive effects on lipid profile in addition to antihyperglycemic effects in diabetic patients. ${ }^{32-37}$ Boswellia serrata gum resin is one of these herbs that has shown its antihyperglycemic and lipidlowering effects in animal studies. ${ }^{21-24,38}$ It also has shown glucose-lowering effect in patients with diabetes through increase in insulin secretion in a clinical report. ${ }^{24}$ In another clinical trial on patients with diabetes, Boswellia serrata gum resin supplementation with the daily dose of $900 \mathrm{mg}$ for 6 weeks showed HDL increasing and LDL decreasing effect. ${ }^{23}$ These effects may be attributed to the main components of this resin, including phenyl propanoids, terpenoids, phenolic compounds, and flavonoids, which were detected by phytochemical 
Table 4. Mean Values $( \pm S D)$ for Fasting Blood Sugar, HbAlc, and Lipids Profile in Boswellia serrata Gum Resin and Placebo Groups Before and After the Intervention.

\begin{tabular}{|c|c|c|c|}
\hline \multirow[b]{2}{*}{ Outcomes } & \multicolumn{2}{|c|}{ Groups } & \multirow[b]{2}{*}{$P^{\mathbf{a}}$} \\
\hline & $\begin{array}{l}\text { Boswellia Gum } \\
\text { Resin }\end{array}$ & Placebo & \\
\hline \multicolumn{4}{|c|}{ Fasting blood sugar (mg/dL) } \\
\hline Before & $17 \mid .82 \pm 60.78$ & $162.18 \pm 56.37$ & .54 \\
\hline After & $149.86 \pm 26.19$ & $165.77 \pm 43.13$ & .09 \\
\hline$P^{\mathbf{b}}$ & .04 & .67 & \\
\hline \multicolumn{4}{|c|}{ Insulin (UI/L) } \\
\hline Before & $7.37 \pm 4.14$ & $5.97 \pm 4.01$ & .20 \\
\hline After & $8.15 \pm 4.90$ & $8.39 \pm 5.48$ & .86 \\
\hline$P^{\mathbf{b}}$ & .48 & .13 & \\
\hline \multicolumn{4}{|l|}{$\mathrm{HbAlc}(\%)$} \\
\hline Before & $8.17 \pm 1.88$ & $8.17 \pm 1.58$ & .98 \\
\hline After & $7.60 \pm 1.34$ & $8.09 \pm 1.48$ & .20 \\
\hline$P^{\mathbf{b}}$ & .02 & .86 & \\
\hline \multicolumn{4}{|c|}{ Triglyceride (mg/dL) } \\
\hline Before & $162.13 \pm 53.53$ & $|4| .07 \pm 64.8 \mid$ & .18 \\
\hline After & $135.93 \pm 31.92$ & $139.74 \pm 66.22$ & .78 \\
\hline$P^{\mathbf{b}}$ & .01 & .88 & \\
\hline \multicolumn{4}{|c|}{ Total cholesterol (mg/dL) } \\
\hline Before & $196.65 \pm 35.74$ & $179.44 \pm 37.65$ & .08 \\
\hline After & $184.27 \pm 29.78$ & $173.96 \pm 44.79$ & .31 \\
\hline$P^{\mathbf{b}}$ & .06 & .43 & \\
\hline \multicolumn{4}{|c|}{ Low-density lipoprotein (mg/dL) } \\
\hline Before & $104.13 \pm 24.23$ & $93.55 \pm 26.71$ & .12 \\
\hline After & $97.72 \pm 34.13$ & $91.81 \pm 29.72$ & .49 \\
\hline$P^{\mathbf{b}}$ & .21 & .68 & \\
\hline \multicolumn{4}{|c|}{$\begin{array}{l}\text { High-density lipoprotein (mg/ } \\
\text { dL) }\end{array}$} \\
\hline Before & $44.48 \pm 10.44$ & $46.03 \pm 11.73$ & .60 \\
\hline After & $47.44 \pm 7.09$ & $43.44 \pm 10.87$ & .10 \\
\hline$P^{\mathbf{b}}$ & .22 & .20 & \\
\hline
\end{tabular}

andependent sample $t$ test.

${ }^{\mathrm{b}}$ Paired sample $t$ test.

assay by thin layer chromatography and previously showed to have hypoglycemic effects. ${ }^{39}$ The major components of the essential oil ( $\alpha$-thujene, $\alpha$-pinene, myrcene, and $p$-cymene) were also present in Anethum graveolens L (dill) seed, another popular antidiabetic plant. ${ }^{40}$

Boswellia serrata gum resin was known as a hot and dry temperament drug and has been recorded as antipyretic, emmenagogue, carminative, antiobesity, and cardiotonic in traditional medicine texts ${ }^{41}$; Boswellia serrata gum resin, especially in traditional Persian medicine, is known as an herbal drug for increasing memory power. ${ }^{42}$ Although it is usually used in combination with multiple other herbs as compound formulations for treatment of gastrointestinal diseases, eye diseases, wounds, and inflammatory diseases, such as osteoarthritis. ${ }^{42}$ But in the current study, we evaluated antihyperglycemic and lipid-lowering effects of Boswellia serrata gum resin as a single herb.

An important limitation of this trial was the short duration of the study. The best median time for following the changes in laboratory test results after pharmacotherapy in diabetic patients is over 2 months. ${ }^{43}$ Moreover, the narrow range of inclusion criteria could lead to some limitations in the generalizability of the study results to all diabetic patients.

Nonresponsive results in our study may be due to small sample size of our study. Within group analysis showed a significant reduction after the intervention in the field of FBS $(P=.04)$, HbA1c $(P=.02)$, and triglyceride $(P=.01)$ in the Boswellia serrata gum resin group, while between groups analysis did not show any statistically significant difference, so small sample size of the study could be one of the causes of this negative results. Moreover, given that positive results of previous studies on antihyperglycemic and lipid-lowering effects of Boswellia serrata gum resin, inadequate prescribed drug dose (500 mg daily) in this study may be another reason for ineffective results. ${ }^{19,23,35}$

As a conclusion, the current study showed that complementary use of Boswellia serrata gum resin capsule with a dose of $250 \mathrm{mg}$ twice daily did not have better outcomes compared with the placebo in FBS, HbAlc, total cholesterol, LDL, HDL, triglyceride, and insulin levels in diabetic patients.

\section{Author Contributions}

The work presented in this article was carried out through collaboration between all authors. HFH and BT made the initial hypothesis. All authors participated in defining the research theme and provided the proposal. SM, SHM, MH, and BT performed the experiments, collected the data, analyzed the data, and wrote the article. HFH and BT conceptualized the study, critically analyzed and discussed the data, and corrected and reviewed the article.

\section{Declaration of Conflicting Interests}

The authors declared no potential conflicts of interest with respect to the research, authorship, and/or publication of this article.

\section{Funding}

The authors disclosed receipt of the following financial support for the research, authorship, and/or publication of this article: This study was supported by a grant from the Iranian Academic Center for Education, Culture and Research (ACECR).

\section{Ethical Approval}

This trial is a 2-arm, double-blind randomized placebo-controlled clinical trial that was registered by the American registry for randomized controlled trials with a code: AEARCTR-0000898. The local Medical Ethics Committee of Qazvin University of Medical Sciences approved the trial protocol and written informed consent was obtained from each patient prior to the study. This study compared Boswellia capsule with placebo and both groups received routine hypoglycemic agents to avoid any deprivation from the standard treatment.

\section{References}

1. Faraji O, Etemad K, Sari AA, Ravaghi H. Policies and programs for prevention and control of diabetes in Iran: a document analysis. Glob J Health Sci. 2015;7:187-197.

2. Shaw JE, Sicree RA, Zimmet PZ. Global estimates of the prevalence of diabetes for 2010 and 2030. Diabetes Res Clin Pract. 2010;87:4-14. 
3. Esteghamati A, Gouya MM, Abbasi M, et al. Prevalence of diabetes and impaired fasting glucose in the adult population of Iran: National Survey of Risk Factors for Non-Communicable Diseases of Iran. Diabetes Care. 2008;31:96-98.

4. Bahadoran Z, Mirmiran P, Hosseinpanah F, Rajab A, Asghari G, Azizi F. Broccoli sprouts powder could improve serum triglyceride and oxidized LDL/LDL-cholesterol ratio in type 2 diabetic patients: a randomized double-blind placebo-controlled clinical trial. Diabetes Res Clin Prac. 2012;96:348-354.

5. Brunzell JD, Davidson M, Furberg CD, et al. Lipoprotein management in patients with cardiometabolic risk: consensus conference report from the American Diabetes Association and the American College of Cardiology Foundation. J Am Coll Cardiol. 2008;51:1512-1524.

6. Bahmani M, Mirhoseini M, Shirzad H, Sedighi M, Shahinfard N, Rafieian-Kopaei M. A review on promising natural agents effective on hyperlipidemia. J Evid Based Complementary Altern Med. 2015;20:228-238.

7. Rahimi R, Shams-Ardekani MR, Abdollahi M. A review of the efficacy of traditional Iranian medicine for inflammatory bowel disease. World J Gastroenterol. 2010;16:4504-4514.

8. Hashempur MH, Heydari M, Mosavat SH, Heydari ST, Shams M. Complementary and alternative medicine use in Iranian patients with diabetes mellitus. J Integr Med. 2015;13:319-325.

9. Samani NB, Jokar A, Soveid M, Heydari M, Mosavat SH. Efficacy of the hydroalcoholic extract of Tribulus terrestris on the serum glucose and lipid profile of women with diabetes mellitus a double-blind randomized placebo-controlled clinical trial. J Evid Based Complementary Altern Med. 2016;21:NP91-NP97.

10. Salimifar M, Fatehi-Hassanabad Z, Fatehi M. A review on natural products for controlling type 2 diabetes with an emphasis on their mechanisms of actions. Curr Diabetes Rev. 2013;9:402-411.

11. Hosseini S, Jamshidi L, Mehrzadi S, et al. Effects of Juglans regia L. leaf extract on hyperglycemia and lipid profiles in type two diabetic patients: a randomized double-blind, placebocontrolled clinical trial. J Ethnopharmacol. 2014;152:451-456.

12. Khalili N, Fereydoonzadeh R, Mohtashami R, Mehrzadi S, Heydari M, Huseini HF. A mixed herbal formulation in the treatment of type II diabetes: a randomized, double-blind, placebocontrolled, clinical trial. J Evid Based Complementary Altern Med. 2017;22:603-608.

13. Ahangarpour A, Zamaneh HT, Jabari A, Nia HM, Heidari H. Antidiabetic and hypolipidemic effects of Dorema aucheri hydroalcoholic leave extract in streptozotocin-nicotinamide induced type 2 diabetes in male rats. Iran J Basic Med Sci. 2014;17: 808-814.

14. Rajaei Z, Hadjzadeh MA, Moradi R, Ghorbani A, Saghebi A. Antihyperglycemic and antihyperlipidemic effects of hydroalcoholic extract of Securigera securidaca seeds in streptozotocininduced diabetic rats. Adv Biomed Res. 2015;4:33.

15. Huseini FH, Mehrzadi S, Ghaznavi H, Tajallizadehkhoob Y, Fakhrzadeh H. Effects of Pinus eldarica Medw. Nut extract on blood glucose and cholesterol levels in hypercholesterolemic alloxan-induced diabetic rats. J Med Plants. 2013;12:68-74.

16. Paranjpe P. Indian Medicinal Plants: Forgotten Healers: A Guide to Ayurvedic Herbal Medicine With Identity, Habitat, Botany,
Photochemistry, Ayurvedic Properties, Formulations \& Clinical Usage. Delhi, India: Chaukhamba Sanskrit Pratisthan; 2001; 1208-1211.

17. Soumyanath A. Traditional Medicines for Modern Times: Antidiabetic Plants. Boca Raton, FL: CRC Press; 2005.

18. Azadmehr A, Ziaee A, Ghanei L, et al. A randomized clinical trial study: anti-oxidant, anti-hyperglycemic and anti-hyperlipidemic effects of olibanum gum in type 2 diabetic patients. Iran J Pharm Res. 2014;13:1003-1009.

19. Upaganlawar A, Ghule B. Pharmacological activities of Boswellia serrata Roxb. Mini review. Ethnobot Leaflets. 2009;13:766-774.

20. al-Awadi F, Fatania H, Shamte U. The effect of a plants mixture extract on liver gluconeogenesis in streptozotocin induced diabetic rats. Diabetes Res. 1991;18:163-168.

21. Zutshi U, Rao PG, Ravi S, Singh GB, Surjeet S, Atal CK. Mechanism of cholesterol lowering effect of Salai guggal ex. Boswellia serrata roxb. Indian J Pharmacol. 1986;18:182-183.

22. Rao AR, Veeresham C, Asres K. In vitro and in vivo inhibitory activities of four Indian medicinal plant extracts and their major components on rat aldose reductase and generation of advanced glycation endproducts. Phytother Res. 2013;27:753-760.

23. Ahangarpour A, Heidari H, Fatemeh RA, et al. Effect of Boswellia serrata supplementation on blood lipid, hepatic enzymes and fructosamine levels in type2 diabetic patients. J Diabetes Metab Disord. 2014;13:29.

24. Ahangarpour A, Akbari Fatemeh Ramezani A, Heidari H, et al. The effect of Boswellia serrata on blood glucose, insulin level and insulin resistance in type 2 diabetic patients. Daneshvar Med. 2013;20:11-18.

25. Masada Y. Analysis of Essential Oils by Gas Chromatography and Mass Spectrometry. New York, NY: Wiley; 1976.

26. MEDCALC. Sample size calculation: comparison of two means. http://www.medcalc.org/manual/sampling_comparison_of_two_ means.php. Accessed April 6, 2018.

27. Kim J, Shin W. How to do random allocation (randomization). Clin Orthop Surg. 2014;6:103-109.

28. Liu JP, Zhang M, Wang WY, Grimsgaard S. Chinese herbal medicines for type 2 diabetes mellitus. Cochrane Database Syst Rev. 2004;(3):CD003642.

29. Hasani-Ranjbar S, Larijani B, Abdollahi M. A systematic review of Iranian medicinal plants useful in diabetes mellitus. Arch Med Sci. 2008;4:285-292.

30. Rouhi-Boroujeni H, Rouhi-Boroujeni H, Heidarian E, Mohammadizadeh F, Rafieian-Kopaei M. Herbs with anti-lipid effects and their interactions with statins as a chemical anti-hyperlipidemia group drugs: a systematic review. ARYA Atheroscler. 2015;11: 244-251.

31. Fugh-Berman A. Herb-drug interactions. Lancet. 2000;355: 134-138.

32. Akbari F, Ansari-Samani R, Karimi A, Mortazaei S, Shahinfard N, Rafieian-Kopaei M. Effect of turnip on glucose and lipid profiles of alloxan-induced diabetic rats. Iran J Endocrinol Metab. 2013;14:492-497.

33. Heydari M, Homayouni K, Hashempur MH, Shams M. Topical Citrullus colocynthis (bitter apple) extract oil in painful diabetic 
neuropathy: a double-blind randomized placebo-controlled clinical trial. J Diabetes. 2016;8:246-252.

34. Huseini HF, Kianbakht S, Hajiaghaee R, Dabaghian FH. Anti-hyperglycemic and anti-hypercholesterolemic effects of aloe vera leaf gel in hyperlipidemic type 2 diabetic patients: a randomized double-blind placebo-controlled clinical trial. Planta Med. 2012;78:311-316.

35. Kassaian N, Azadbakht L, Forghani B, Amini M. Effect of fenugreek seeds on blood glucose and lipid profiles in type 2 diabetic patients. Int J Vitam Nutr Res. 2009;79:34-39.

36. Mozaffari-Khosravi H, Jalali-Khanabadi BA, Afkhami-Ardekani M, Fatehi F. Effects of sour tea (Hibiscus sabdariffa) on lipid profile and lipoproteins in patients with type II diabetes. J Alternat Complement Med. 2009;15:899-903.

37. Shehata AM, Quintanilla-Fend L, Bettio S, Singh CB, Ammon HP. Prevention of multiple low-dose streptozotocin (MLD-STZ) diabetes in mice by an extract from gum resin of Boswellia serrata (BE). Phytomedicine. 2011;18:1037-1044.
38. Alam M, Khan H, Samiullah L, Siddique KM. A review on phytochemical and pharmacological studies of Kundur (Boswellia serrata Roxb Ex Colebr.) - a unani drug. J Appl Pharm Sci. 2012;2:148-156.

39. Vinayagam R, Xu B. Antidiabetic properties of dietary flavonoids: a cellular mechanism review. Nutr Metab (Lond). 2015;12:60.

40. Goodarzi MT, Khodadadi I, Tavilani H, Abbasi Oshaghi E. The role of Anethum graveolens L.(dill) in the management of diabetes. J Trop Med. 2016;2016:1098916.

41. Ahmadian M, Hashemian M, Abadi ZM. Prevalence of the use of Frankincense in postpartum women at maternity wards of Mashhad, Iran in 2011-2012. Avicenna J Phytomed. 2015;5(suppl):6.

42. Khorasani MA. Makhzan al Advieh. Tehran, Iran: Bavardaran Press, Research Institute for Islamic and Complementary Medicine, Iran University of Medical Sciences; 2001.

43. Yood UM, Lafata JE, Koro C, Wells KE, Pladevall M. Time to pharmacotherapy change in response to elevated HbAlc test results. Curr Med Res Opin. 2006;22:1567-1574. 